Article

\title{
Cytochrome P450 CYP6EV11 in Chironomus kiiensis Larvae Involved in Phenol Stress
}

\author{
Qihui Zhang, Dong Chu, Lili Sun and Chuanwang Cao * \\ College of Forestry, Northeast Forestry University, Harbin 150040, China; secertzhang@163.com (Q.Z.); \\ dongtianderuguo@163.com (D.C.); sunlilinefu@126.com (L.S.) \\ * Correspondence: chuanwangcao@nefu.edu.cn or chuanwangcao@126.com; Tel.: +86-451-8219-1822
}

Received: 22 February 2018; Accepted: 28 March 2018; Published: 9 April 2018

\begin{abstract}
Phenol is one of the organic pollutants which can cause water environment pollution. It is not only enriched in aquatic organisms but is also a serious threat to human health. Chironomus kiiensis is very sensitive to the contaminants in water and its cytochrome P450s are usually chosen as biomarkers for water pollution. To examine whether CYP6EV11 plays a role in the oxidative metabolism of phenol, we measured the silencing efficiency of CYP6EV11 and evaluated larval susceptibility to sublethal phenol levels by RNA interference (RNAi) technology. The results showed that the transcription of CYP6EV11 was found significantly up-regulated when the 4 th instar C. kiiensis larvae were exposed to three doses of phenol. However, the transcriptional levels of CYP6EV11 were significantly suppressed by $92.7 \%$ in the 4 th instar C. kiiensis larvae soaked in $d s C Y P 6 E V 11$ compared with those soaked in dsGFP for $6 \mathrm{~h}$. The CYP6EV11 expression and mortality of the 4th instar C. kiiensis larvae with CYP6EV11 silencing were mostly decreased under phenol stress. Therefore, the CYP6EV11 gene may be used as a molecular biomarker for earlier warning and monitoring for water pollution.
\end{abstract}

Keywords: CYP6EV11; phenol stress; Chironomus kiiensis; molecular biomarker

\section{Introduction}

Phenol (carbolic acid, phenolic acid, phenylic acid or oxybenzene) consists of an aromatic ring linked a hydroxyl group and is widely used as the precursor to produce industrial compounds such as kerosene, phenolic resin and pesticides [1]. The compounds penetrat ecosystems due to the drainage off municipal or industrial sewage to surface water [2]. The Environmental Protection Agency (EPA) specified the standard maximum of phenol contaminant level of $1 \mathrm{mg} / \mathrm{L}$ in wastewater [3]. Since the phenolic compounds were stable over a long term and harmful to organisms at low dose, many of them have been classified as hazardous pollutants due to their harmful damage to human health [4]. Although the standards of critical toxic concentration of phenol were much different, and varied from $1.06 \mu \mathrm{M}$ to $105.24 \mu \mathrm{M}(105.24 \mathrm{mM}$ in Malaysia,10.63 mM in the United States, $1.06 \mathrm{mM}$ in Australia) [5-7], there is no doubt that phenol is harmful and should be monitored. Our previous research also found that the enzymatic activities in Propsilocerus akamusi were significantly altered in response to phenol [8].

Cytochrome P450s (CYPs) belong to a superfamily, which is found in all organisms that play an important role in many physiological processes such as the metabolism of fatty acids, steroids and vitamin D as well as some other phytochemicals like pesticides [9]. It is well documented that CYPs are associated with the process of detoxification in insects, and the elevated activity of CYP enzymes has the ability to accelerate metabolism of pesticides. The CYP6 families in terrestrial invertebrates have frequently been shown to play a role in the detoxification of xenobiotics and metabolic resistance to insecticides [10-15]. Most CYP6 genes in insects have been shown to enhance metabolic detoxification, 
such as CYP6AB37, CYP6AB35, CYP6B53, CYP6AB3, CYP6AB32, CYP6AB33, CYP6AB36, CYP6CT4 and CYP6AN15v1 of Lymantria dispar [15]. It has been reported that CYP6BQ23 in Meligethes aeneus is associated with the resistance to deltamethrin [16]. In several species of Chironomus, different toxic compounds are affected by the expression of the CYP6 gene. For example, the mRNA levels of CYP6B7 in Chironomus riparius are evaluated after exposures to the ultraviolet filters benzophenone-3 (BP3) and 4-methylbenzylidene camphor (4MBC) [17] and the antibacterial agent triclosan [18]; in C. tentans the transcriptional activities of CYP6EX3 and CYP6EV1, CYP6EV3 have been studied after atrazine and chlorpyrifos exposures. Moreover, the present study has reported the effects of phenol on the expression of ten CYP6 genes in C. kiinensis [19]. On the other hand, other cytochromes in different Chironomus species have been analyzed as possible biomarker genes that could be useful in ecotoxicological studies, risk assessment and bioremediation, such as CYP4G [20], CYP9AT2 [21], CYP4D2, CYP9F2 and CYP12A2 in C. riparius [18]; CYP4DG1, CYP4DG2 and CYP9AT1 in C. tentans [22,23].

Chironomidae are known as non-biting midges belonging to a family of Diptera: Nematocera. They often distribute in urban and residential areas in close proximity to polluted and eutrophic waters causing a big problem worldwide [24]. Chironomus kiinensis is broadly distributed in Malaysia, Japan, USA and South China [25]. C. kiinensis could be used extensively for acute or chronic bioassays in fresh water ecosystems as it has a relatively short life cycle, and due to the ease of maintenance of laboratory cultures and relative sensitivity to aquatic contaminants [26]. To provide molecular evidence of CYP gene detoxification that will be of benefit to further monitor water pollution, we: (1) examined the transcriptional responses of CYP6EV11 in C. kiiensis to the exposure of phenol at different concentration; (2) revealed the phenol-induced down-regulation of CYP6EV11 contributing to decreased toxicity of phenol to C. kiiensis using the RNA interference (RNAi) method. These results may potentially develop sensitive molecular markers of Chironomidae for monitoring pesticide exposures in non-target organisms in aquatic systems.

\section{Results}

\section{1. cDNA Cloning and Characterization}

In databases, full-length cDNA of CYP6EV11 was detected in the P450 family genes, with open reading frames (ORFs) of 1476 bp encoding 491 amino acids, with predicted molecular masses of $56.79 \mathrm{kDa}$ and isoelectric points (PI) of 9.12. Besides, there are no signal peptides in CYP6EV11.

\subsection{Polygenetic Analysis}

Based on the identities of CYP6EV11, phylogenetic trees were constructed with 22 genes of high homologous amino acids in insects. The CYP6EV11 and CYP6EV10 (AHJ10931.1) in C. kiiensis shared the highest sequence similarity $(71 \%)$, and were clustered into a group. All the $22 \mathrm{CYP}$ sequences have been deposited in the NCBI database with their accession numbers as shown in the Figure 1. Five similar motifs were found in typical CYPs, including helix-C, helix-I, helix-K, Meander domain and heme-binding domain from $\mathrm{N}$ to $\mathrm{C}$ terminal (Figure 2). Helix-C is heme-interacting region with typical sequences WxxxR; AGxET motif is located in helix-I and reportedly to make an oxygen binding pocket; E/SxLR located in helix-K with the hydrogen bonding domain and PxxFxPxxF motif are thought to form a set of salt bridge interactons (E-R-R) for stabilizing the structure of protein [27]; and the P450 heme-binding domain locates at the $3^{\prime}$-end with the FxxGxRxCxG/A sequences [28,29]. 


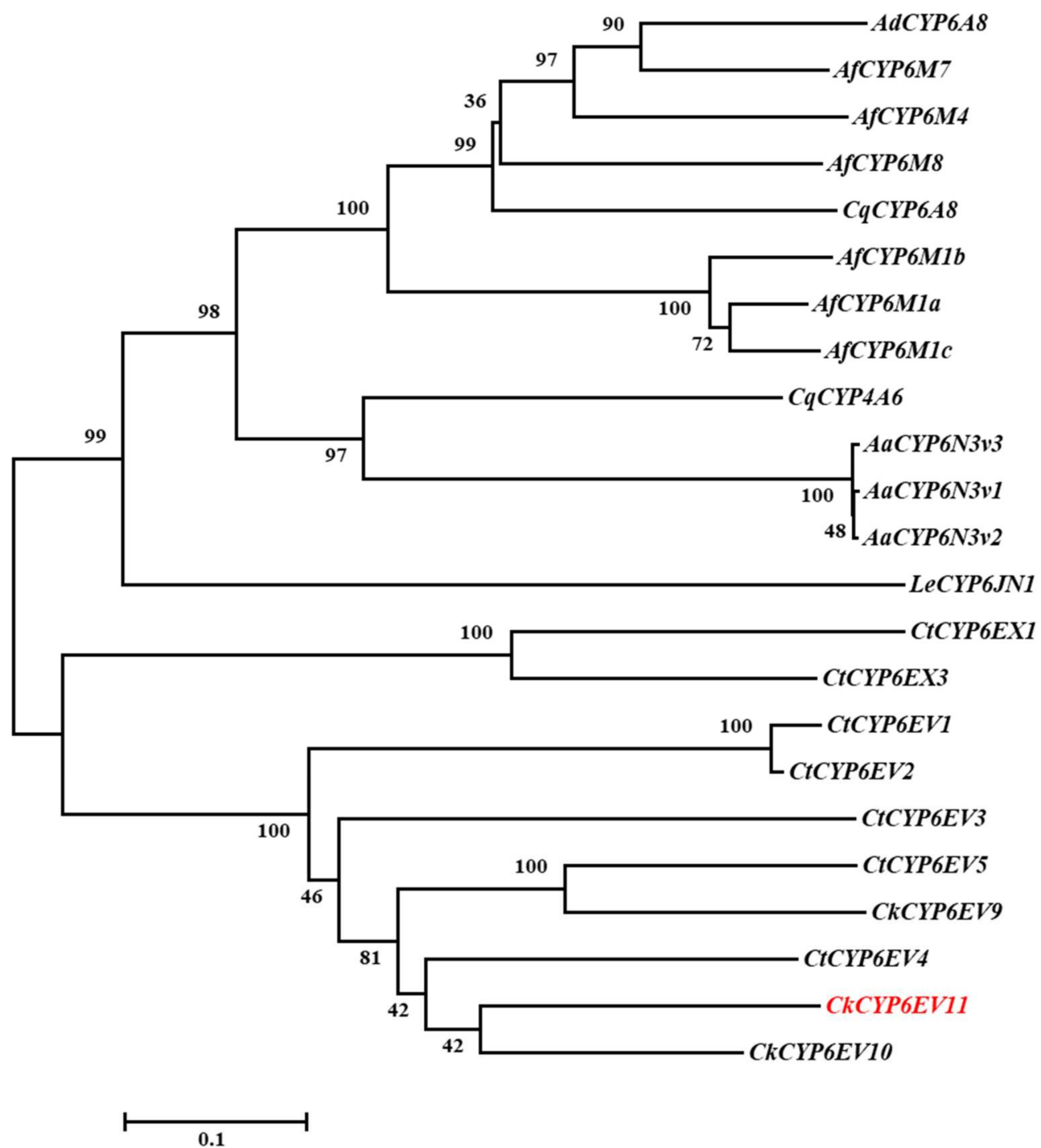

Figure 1. Phylogenetic tree of $23 \mathrm{CYP}$ genes are from 7 insects. These genes were downloaded from the National Center for Biotechnology Information (NCBI) databases. The gene accession numbers are parenthesized. The CYP genes are CtCYP6EV1 (ARO50426.1), CtCYP6EV2 (ARO50430.1), CtCYP6EV3 (ARO50428.1), CtCYP6EV4 (ARO50429.1), CtCYP6EV5 (ARO50442.1), CtCYP6EX1 (ARO50434.1), CtCYP6EX3 (ARO50425.1), CkCYP6EV9 (AHJ10930.1), CkCYP6EV10 (AHJ10931.1), CqCYP4A6 (XP_001867280.1), CqCYP6A8 (XP_001870174.1), AaCYP6N3v1 (AAF97936.1), AaCYP6N3v2 (AAF97937.1), AaCYP6N3v3 (AAF97938.1), AdCYP6A8 (ETN65670.1), AfCYP6M1a (AFM08393.1), AfCYP6M1b (AFM08394.1), AfCYP6M1c (AFM08395.1), AfCYP6M4 (AFM08397.1), AfCYP6M7 (AIE17403.1), AfCYP6M8 (AFM08398.1), LeCYP6JN1 (ALX81394.1), CkCYPEV11. CkCYP6EV11 is a target gene in this study from Chironomus kiiensis, which was obtained from transcriptome sequencing in our previous study [26]. These genes are from Chironomus tentans, Chironomus kiiensis, Culex quinquefasciatus, Aedes albopictus, Anopheles darling, Anopheles funestus and Liposcelis entomophila. 


\section{$\Downarrow \downarrow$}

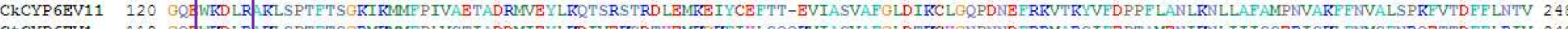

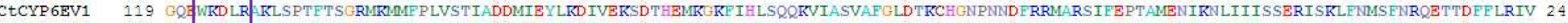

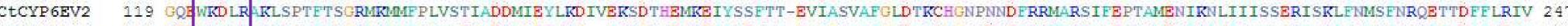

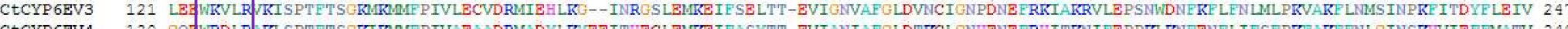

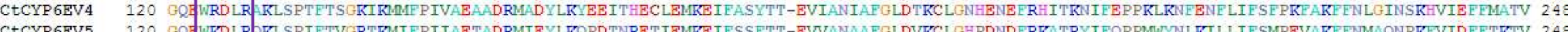

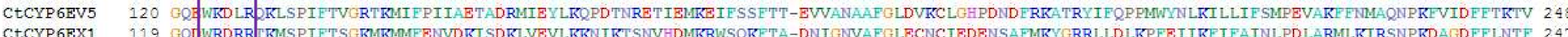

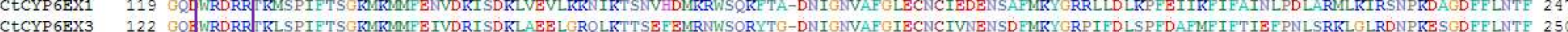
CKCYPGEV9 120 (1)

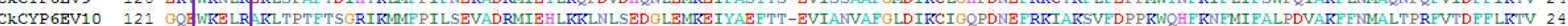

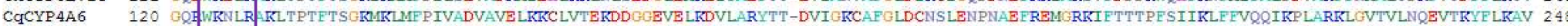

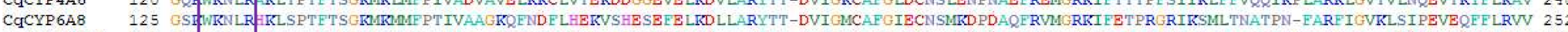

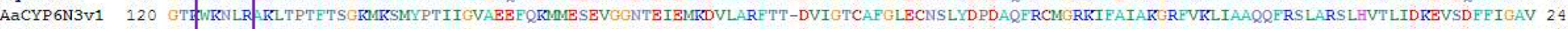

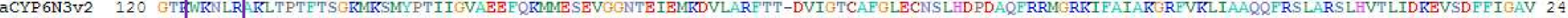

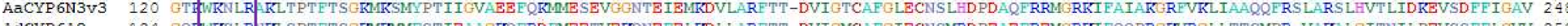

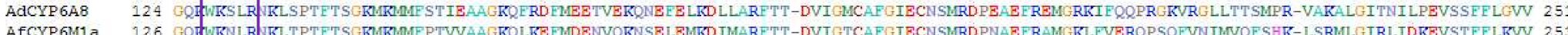

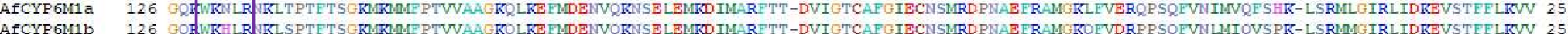

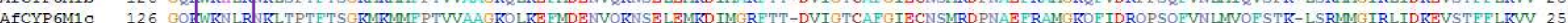

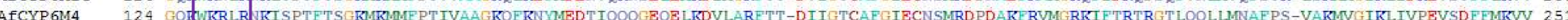

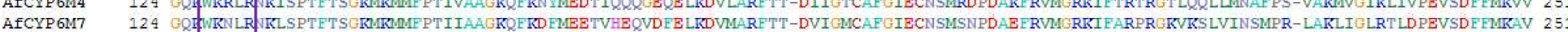

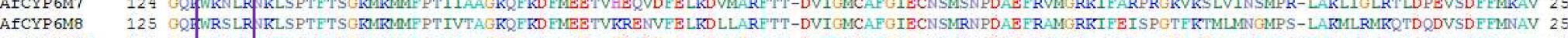

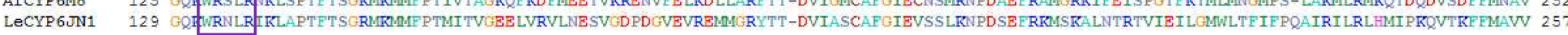

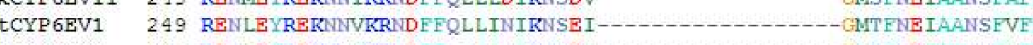

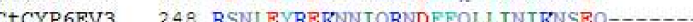

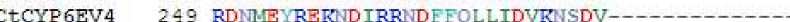
CTCYP6EV5 249 RDWHTERETRNIORDDFFOLLTNTKK-DE--

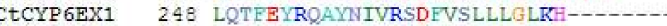
CtCYP6EX3 251 LQTLEYRORNNIORNDFVSLLLGLKD--

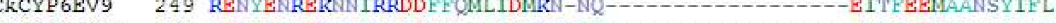

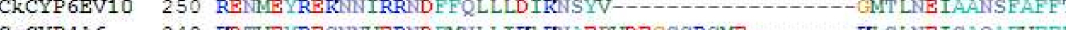

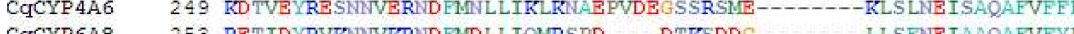

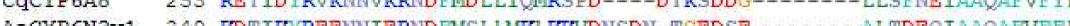
C DIVIB

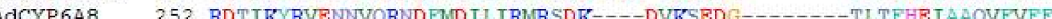

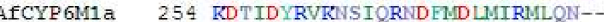

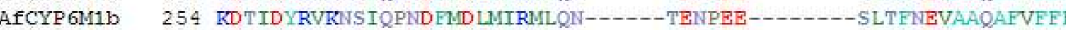

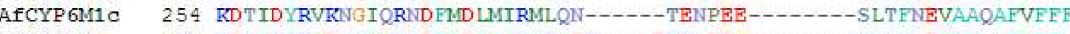

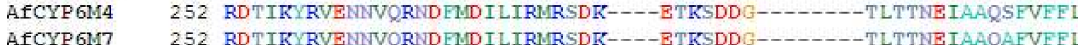

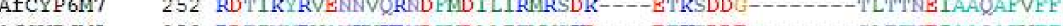
AfCYP WM8 253 RDT INYRVANAKVKRND FVD LLITMASKRD----ETRSDDE-------SLTFNEIAAQAFVEFH

Wh SAMTECTYR LALNHG IODRLRKE IEEVLRRYNGELTYYAAIAEMTXYDD

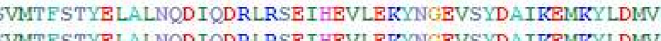
SCSYR LALNOD IODRLRTEIDEVIKKHKGEVTYDAIARMEYLSKV

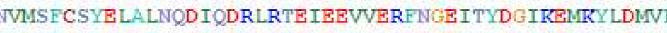
IAITFCTYELAFNQD IQDRLRTEIETVLKKKD GDVTYDATMEMTKYLEMV I

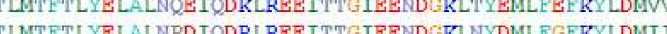
W

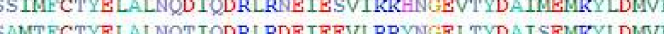

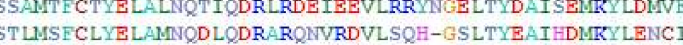

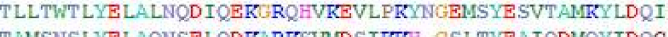

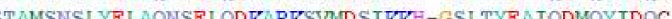

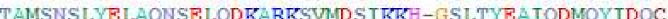
TTLLTETLVRLALOPEVOEK ROCVIKEVI IRRHNGLLTYESVI RMOYLDOI

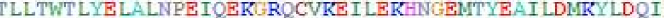
TLLTWT LYE LALNPEIQEKGRKCVKE I LEKHNGEMTYEAI LDMKYLDOI

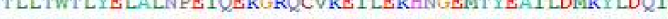
S LATF L Y LALNPE IOEQARNCVKEVLDRYGGELTYEAALEMDYLDRV ST LLTET LYR LALNODVODK RRCVKEVLDRHNGER LTYDAMMEMHY LDQI

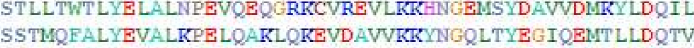

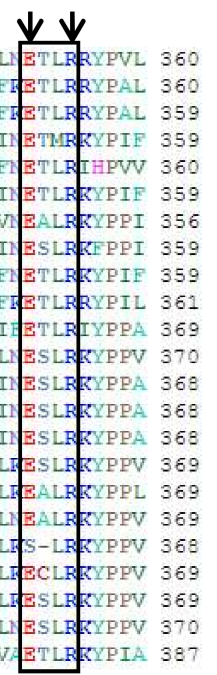

Figure 2. Cont. 


\begin{tabular}{|c|c|c|c|c|c|c|c|}
\hline & & & & & & & \\
\hline & & & EREDPER & & SEORRTCI & & \\
\hline CYP 6EVI & 361 & 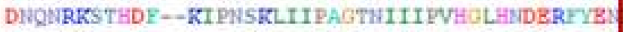 & PEETDPER: & II KKRESEVYIE & ESBOURUCI & SEKTSIPFQEFPTVEROTPLGOAOLKLOR & \\
\hline CYP6EV2 & 360 & 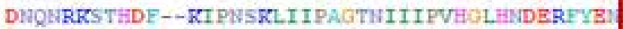 & & & & MULKLOR. & \\
\hline CYP6EV3 & 360 & SKOF $-\mathrm{KRIP}$ & & & ESEa & ISLTSSFOSPREMGMLLLIBZ & \\
\hline CtCYP 6EVA & 361 & 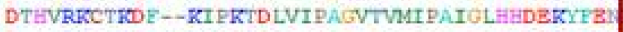 & DVEDERNR & SDERVKRLLVHTEIB & SEGHRNCI & CREOTMQIKIOLVKLLRNERIFPCNKT LVEMRTTEASISEQSALGCMNLKLEH & \\
\hline CtCYP6EV5 & 360 & EVQVRKCIKSETMRMPDSELAIPIOTPVLIFVAGIHUDERYFR| & PEKTDPER & SBEUIRILVPHTEIF & SEOPRNCI & 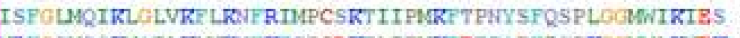 & \\
\hline & 357. & & & & & & \\
\hline CYP6EX3 & 960 & 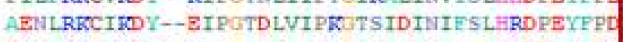 & & & & & \\
\hline CKCYP6EV9 & 360 & BVQIRECTKEY--KIPOTHLIIHSCMPILIPVIOIHMERVFI| & PEKFDPRR & NBEIVIKKLVPHTYVE & SEOPRNCI & 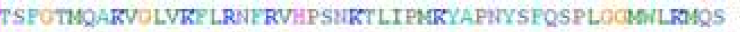 & \\
\hline CKCYP6EV10 & 362 & 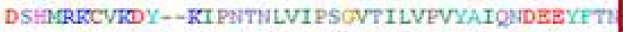 & PEKPDPERT & IEESVIKKO I PETIME & & 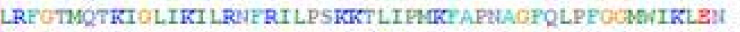 & \\
\hline & 370 & & & & & & \\
\hline & 371 & PIHFREVAKDY --QVPWTKSVLEAOTOVEIPVYOIH & PER: & IWTE & cip & 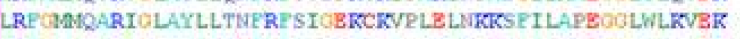 & \\
\hline CYP6N3v1 & 369 & 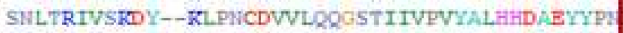 & Pen & TPEEVAKRA & ER: & RVLLAYLLRDESETLSSKIPVPLK & \\
\hline CYPGN3V2 & 369 & SELTRIVSEDY - KLP & & IPE & & RVOLAYLLKDFSETLSSKTPVPLKI & \\
\hline 13v3 & 369 & SinL & & & & & \\
\hline ICYPGAB & 370 & PVHFRVTS: & & SPE & & 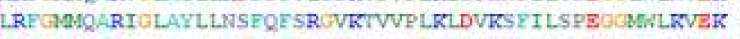 & \\
\hline Afcre6M1a & 370 & PTHIRVAR & & SPBEBAR & & 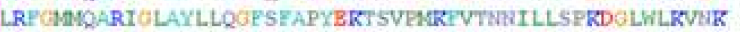 & \\
\hline t11 & 370 & 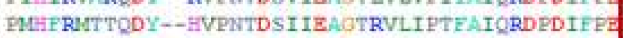 & $\operatorname{Eer}$ & SPE: & & 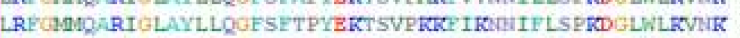 & \\
\hline & 369 & & & & & & \\
\hline 196 & 370 & svi & & & & RIOLIHLLTSEREACCSKTPIPMEYDI TNTILSPKUMG/LRNEK & \\
\hline Exp6197 & 970 & PVHFRTTSKEY-_QVPOTKTVLEAOTSVMVVYYAIHRDEEHFP/ & EDL & TPEEZAKRHPY & eOB: & 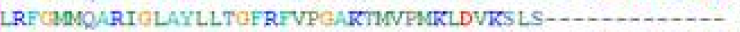 & \\
\hline & 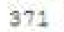 & SRDY--QVPOTESVLGAGTAVMVPVHAIH & & & & LDGFQFAPSSKTVIPAELSTBS: & \\
\hline & & & & & & & \\
\hline
\end{tabular}

Figure 2. The alignment of deduced amino acid sequences from 23 CYP genes from seven insects. The five important conserved motifs of the CYPs were framed by only partial sequence alignment. The purple box shows helix-C with conserved sequences WxxxR; blue box indicates helix-I with typical sequences AGxET; and dark box highlights helix-K with sequences E/SxLR. The heme-binding domain is boxed in pink with typical residues FxxGxxxCxG/A and the conserved Meander domain was boxed in red with conserved sequences PxxFxPxxF. The similarity of CYP6EV11 with CkCYP6EV10, CtCYP6EV4, CtCYP6EV5, CkCYP6EV9, CtCYP6EV2, CtCYP6EV3, CtCYP6EV1, CtCYP6EX3, AfCYP6M8, CqCYP6A8, AfCYP6M4, AdCYP6A8, AaCYP6N3v3, AaCYP6N3v2, AaCYP6N3v1, AfCYP6M7, CqCYP4A6, AfCYP6M1b, AfCYP6M1a, CtCYP6EX1, LeCYP6JN1, AfCYP6M1c is 71\%, 64\%, 63\%, 61\%, 58\%, 56\%, 56\%, 47\%, 43\%, 44\%, 44\%, 43\%, 42\%, 41\%, 42\%, 43\%, 42\%, 45\%, 45\%, $44 \%, 41 \%, 44 \%$, respectively. 


\subsection{Expression Profiling under Phenol Stress}

QRT-PCR analysis was performed to compare the transcription levels of CYP6EV11 under the three doses of phenol stresses. The CYP6EV11 was significantly up-regulated by 1 and $100 \mu \mathrm{M}$ of phenol, respectively. However, CYP6EV11 was suppressed by phenol at the dose of $10 \mu \mathrm{M}$ at $6 \mathrm{~h}$. After the larvae were stressed for 12 96 h, the expressions of CYP6EV11 were significantly up-regulated under three doses of phenol stresses. As the results of induced expression of CYP6EV11 at $1 \mu \mathrm{M}$ phenol stress, $1 \mu \mathrm{M}$ was chosen as the dose of treatment to explore the effects of gene silencing on development and response to phenol stress (Figure 3).

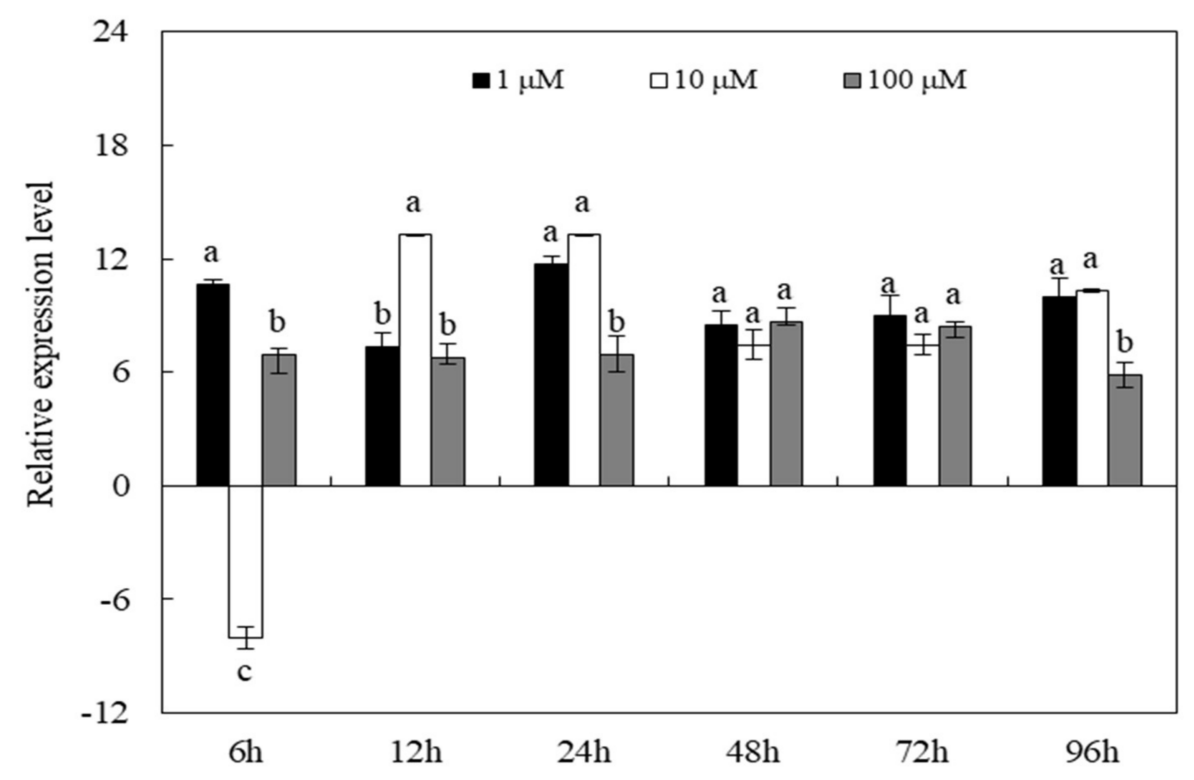

Figure 3. Transcriptional profiles of CYP6EV11 in the 4th instar C. kiiensis larvae following exposure to three doses of phenol $(1,10$ and $100 \mu \mathrm{M})$ during a 96-h period. The larvae without phenol treatment were regarded as controls. The standard error (SE) bars were calculated based on three experimental replicates. The bars with different letters $(\mathrm{a}-\mathrm{c})$ are significantly different at $p<0.05$ based on one-way ANOVA followed by Duncan multiple comparisons. All of the relative expression levels were $\log 2$ transformed.

\subsection{Gene Silencing Analysis}

To determine whether $d s C Y P 6 E V 11$ could inhibit the expression of CYP6EV11, the 4th instar larvae of C. kiiensis were soaked in dsCYP6EV11 and larvae soaked in dsGFP were chosen as the controls; qRT-PCR analyses showed that the CYPEV11 transcript level was reduced at three of four times, especially, the CYPEV11 transcript level was reduced by $92.7 \%$ at $6 \mathrm{~h}$ compared with those soaked in $d_{s} G F P(p<0.05)$. However, the CYPEV11 transcript level was increased by $182.3 \%$ at the time point of $24 \mathrm{~h}$ (Figure 4 ).

Meanwhile, the mortality rate was recorded to explore the effects of gene silencing on the growth of larvae. The results showed that the mortality rate of each treatment gradually increased with the increasing of silencing time. However, there were no statistical differences in the mortality rates between the larvae soaked in $d_{s C Y P E V 11}$ and $d_{S}$ GFP at the period of $3 \sim 24 \mathrm{~h}$. The mortality rate of larvae soaked in $d s C Y P 6 E V 11$ reached the highest at $72 \mathrm{~h}$, which was $24.9 \%$ more than observed for the $d_{s} G F P$ treatment (Figure 5). 


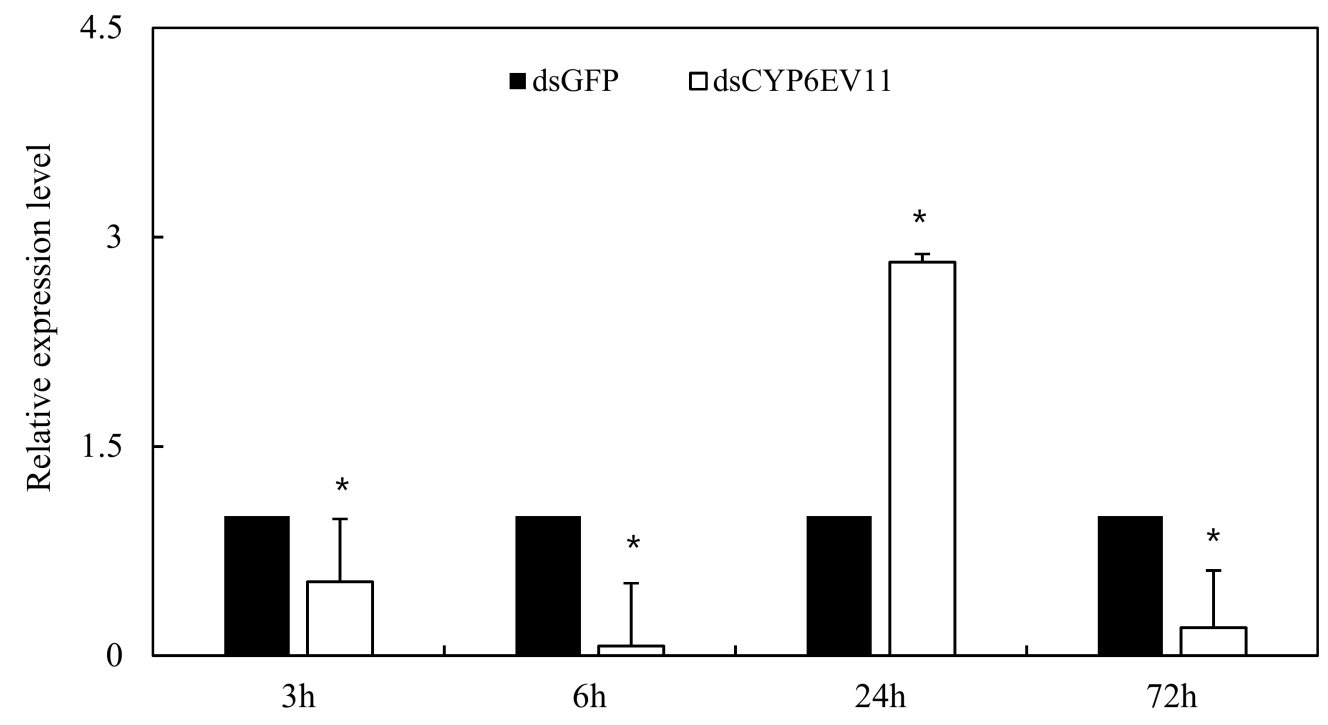

Figure 4. The CYPEV11 transcriptional level in C. kiiensis soaked in dsCYPEV11 compared with those soaked in $d s G F P$. The asterisk $\left({ }^{*}\right)$ on the SE bars indicate significant differences between treatments and controls $(p<0.05)$.

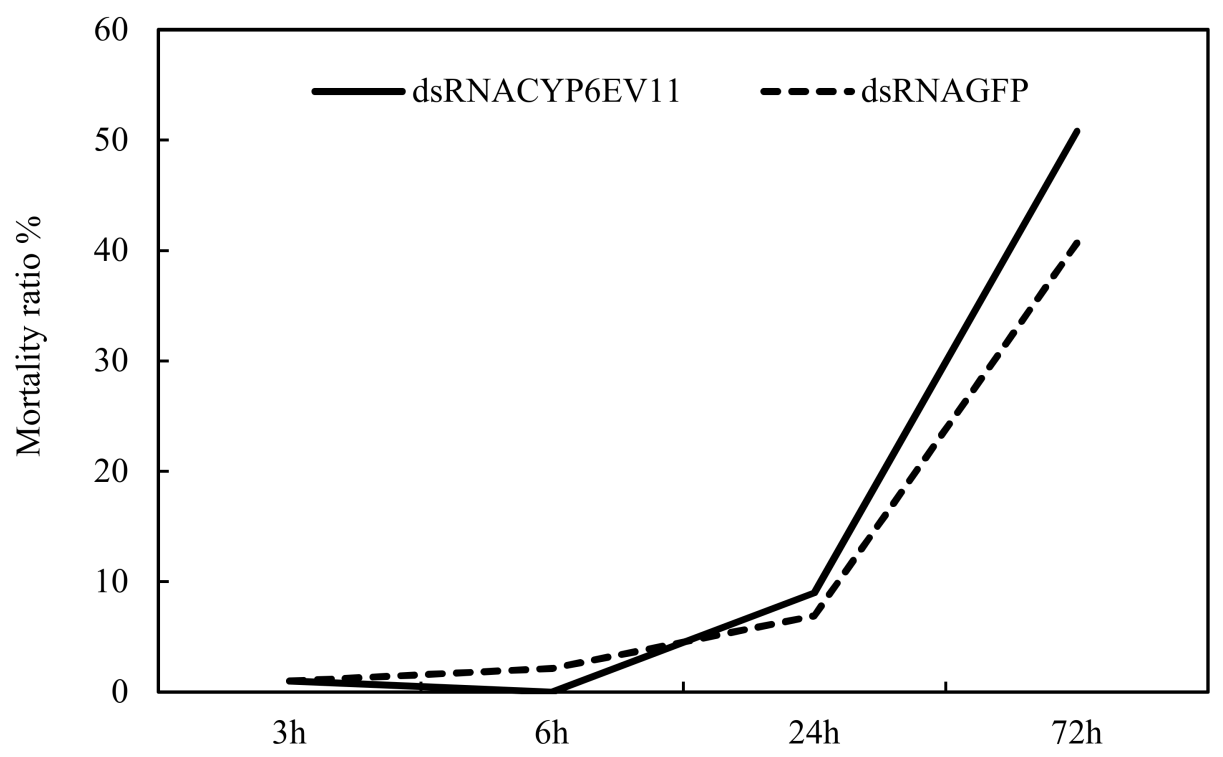

Figure 5. The mortality rate of $C$. kiiensis larvae with CYP6EV11 gene silencing and the groups soaked in $d s G F P$.

\subsection{Effects of Gene Silencing on Development and in Response to Phenol Stress}

Since the transcript levels of CYP6EV11 were successfully suppressed in larvae soaked in $d s R N A$, we further examined whether the suppression of CYP6EV11 transcript had effects on CYP6EV11 in response to phenol stress. CYP6EV11 was mostly suppressed after 3-h treatment, the transcript level was reduced by $99.9 \%$ compared with what was observed in those soaked in $\operatorname{dsGFP}(p<0.05)$. However, the CYPEV11 transcript level was increased by $180.5 \%$ compared with the larvae soaked in $d s R N A$ for $6 \mathrm{~h}$. After $72 \mathrm{~h}$ of stress, the susceptibility of larvae to phenol gradually decreased and the transcript level was reduced by $77.9 \%$ (Figure 6).

The mortality rates of $d s C Y P 6 E V 11$ and $d s G F P$ treatments gradually increased with the increase of silencing time. After the larvae were treated with a mixture (phenol at $1 \mu \mathrm{M}$ and $d s R N A$ at $2 \mu \mathrm{g} / \mu \mathrm{L}$ ) for $24 \mathrm{~h}$, all the mortalities of $d s C Y P 6 E V 11$ groups were significantly higher than those of $d s G F P$ groups 
$(p<0.05$, Figure 7). Especially, the mortality of $d s C Y P E V 11$ treatment increased by $70.5 \%$ compared with the larvae soaked in $d s G F P$ at the 72 -h time point.

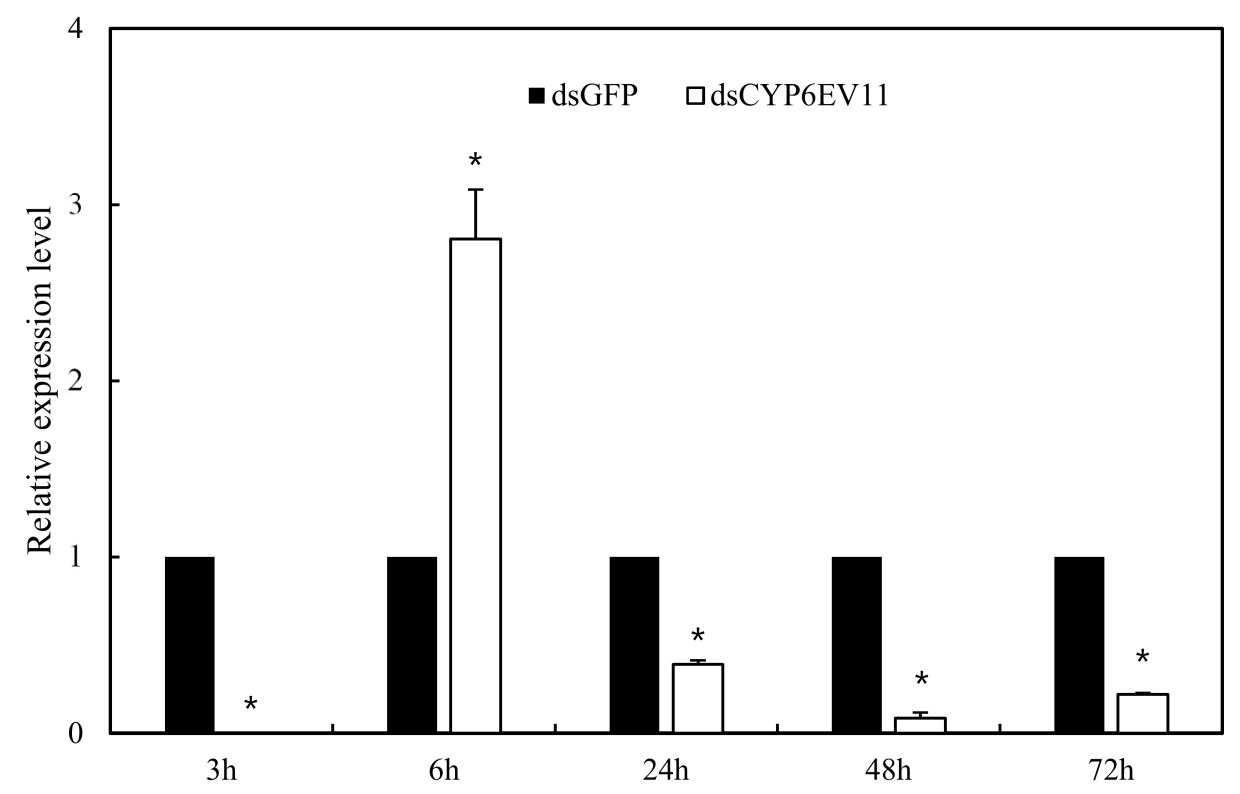

Figure 6. Transcriptional levels of CYP6EV11 in silenced C. kiiensis larvae in response to phenol stress. The larvae treated with $d_{S G F P}$ were regarded as control. The SE bars were calculated based on three experimental replicates. The asterisk $\left(^{*}\right)$ on the SE bars indicate significant differences between treatments and controls $(p<0.05)$.

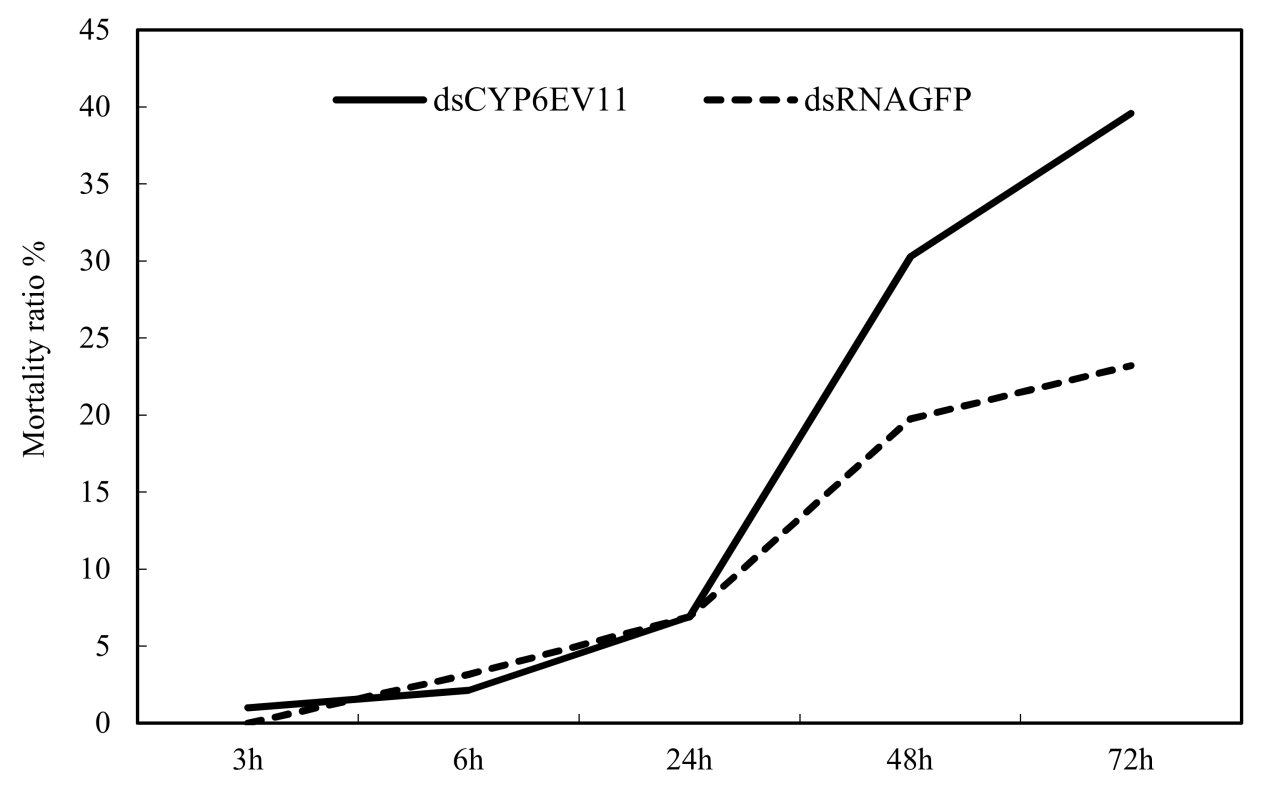

Figure 7. The mortality rates of $C$. kiiensis larvae with CYP6EV11 gene silencing under phenol stress. The larvae were soaked in the mixture phenol at $1 \mu \mathrm{M}$ and $d s R N A$ at $2 \mu \mathrm{g} / \mu \mathrm{L}$, and the groups soaked in $d s G F P$ were regarded as controls to compare the susceptibility to phenol after CYP6EV11 gene silencing.

\section{Discussion}

Insect cytochrome P450s are known to play an important role in detoxifying insecticides and plant toxins $[15,30]$. The up-regulation of CYPs, especially the members of the CYP6 family, has been confirmed to be associated with enhanced metabolic detoxification of insecticides in insects [16,31-34]. 
In this study, the transcripts of CYP6EV11 treated with phenol were found to be significantly up-regulated compared to those in the untreated groups. The increased expression of CYP6EV11 may imply an enhanced ability to metabolize exogenous compounds. Our pervious study also found that the CYP6FV2 and CYP6FV1 in 4th instar C. kiinensis larvae were mainly up-regulated during a 96-h phenol exposure [19]. As a result of stress, similar differential transcriptional expression levels have been reported in $C$. tentans. Tang et al. (2018) reported stress-related genes in C. tentans, including two cytochrome P450 genes (CYP6EV1 and CYP4DG2), have considerable potential as sensitive biomarkers for the diagnosis of chlorpyrifos contamination [22]. The expressions of CYP6EX3 and CYP6EV3 in C. tentans can also be significantly up-regulated by atrazine at 1000 and $5000 \mathrm{mg} / \mathrm{L}$, respectively [23]. Thus, upregulation of the CYP4G gene in Chironomus riparius was found after exposures to TBTO (1 ng/L $24 \mathrm{~h}-0.1 \mathrm{ng} / \mathrm{L} 96 \mathrm{~h}$ ) [20].

To reveal the role of CYP6EV11 in pollutant metabolism, RNAi technology was used in this study. RNAi has been successfully used in most insects like Lepidoptera and Coleoptera, but rarely used in Chironomidae [35-37]. Lu et al. (2012) had successfully revealed two acetylcholinesterase genes (TcAce1 and TcAce2) in Tribolium castaneum by the method of gene silencing [38]. Knockdown of CYP6EV11 was successfully conducted by this method, and a similar method was also applied for CYP6EX3 silencing to investigate the susceptibility of $C$. tentans larvae to chlorpyrifos [23]. Compared with dsGFP groups, CYP6EV11 expression was significantly decreased in C. kiiensis larvae soaked in $d_{s C Y P 6 E V 11}$ under phenol and non-phenol stresses. The results showed that CYP6EV11 played a role in oxidative metabolism to phenol. Interestingly, the $C$. kiiensis larvae decreased susceptibility to phenol when the CYP6EV11 was silenced resulted in low mortality indicating other CYP family genes may be triggered to increase resistance to phenol stress. This result is consistent with the report of Cao et al. (2016) [19]. RNAi technology with $d s R N A$ soaking was used to further study gene function of Chironomidae. Our results have provided, for the first time, crucial evidence with regard to which CYP6EV11 in C. kiiensis may be a new molecular biomarker for monitoring phenol pollution and, therefore, the extension in other species is available. Further studies should validate the metabolism ability by heterologously expressed CYP6EV11 in C. kiiensis.

\section{Materials and Methods}

\subsection{Experimental Midge Rearing}

The Chironomus kiiensis were obtained from Shenzhen Municipal Water Affairs Bureau, China, and were cultured according to the method of Cao et al. (2013) [26]. Briefly, the C. kiiensis were reared in mixed-age cultures by generation to generation under the condition of $20 \pm 2{ }^{\circ} \mathrm{C}$ and L16:D8. The midges were fed with goldfish granules (Beijing San You Beautification Free TECH. Co., Ltd., Beijing, China) and maintained in a glass tank $(50 \mathrm{~cm} \times 20 \mathrm{~cm} \times 30 \mathrm{~cm})$ that was covered with nylon net.

\subsection{Cloning and Identification of CYP6EV11}

Total RNA was isolated using an RNeasy Mini Kit (Qiagen, Valencia, CA, USA) following the manufacturer's guidelines and treated with RNase-free DNase I (Qiagen, Madison, WI, USA). RNA concentrations were measured using a spectrophotometer, and RNA integrity was checked by analysis on a $1.0 \% w / v$ agarose gel. The $C$. kiinensis transcriptome was profiled by conducting Solexa sequencing at the Beijing Genomics Institute (BGI) (Shenzhen, China) [26].

The cDNA of CYP6EV11 was cloned by the method of RACE using 3'-Full RACE Kit and 5'-Full RACE Kit (TaKaRa, Kyoto, Japan), and was purified using E.Z.N.A. Gel Extraction Kit (Omega, Norcross, GA, USA). After purity and quality checks, the open reading frames (ORFs) were confirmed using the ORF finder (Available online: http://www.ncbi.nlm.nih.gov/gorf.html). The molecular masses, isoelectric points (PI) and the conserved domains were derived using ProtParam (Available online: http://au.expasy.org/tools/protparam.html) and Conserved Domains (Available online: http:/ / www.ncbi.nlm.nih.gov/Structure/cdd/wrpsb.cgi) of NCBI, respectively. SignalP3.0 Server 
(Available online: http://www.cbs.dtu.dk/services/SignalP) was used to compute signal peptide of the CYP6EV11 $\mathrm{h}$.

\subsection{Multiple Sequence Alignment and Polygenetic Analysis}

Amino acid sequences corresponding to CYP6 in other insects were retrieved from the NCBI database (Available online: http:/ /www.ncbi.nlm.nih.gov/BLAST/) for multiple sequence alignment using CLUSTALX 1.83(Institut de Genetique et de Biologie Moleculaire et Cellulaire, Illkrich, France). The phylogenetic tree was constructed by the neighbor-joining method and bootstrapped with 1000 replicates to evaluate the branch strength using MEGA 5.1 software(CEMI, Temp, AZ, USA) [39].

\subsection{C. kiiensis Larvae Stress and RNAi Analysis}

The larvae were exposure to phenol $(0,1,10,100 \mu \mathrm{M})$ with ten replicates of each treatment. Thirty 4th instar larvae with similar size and body color were randomly assigned in each replicate. The controls were maintained without any exposure to chemicals for the different durations and concentrations along with the phenol-exposed samples. After exposure, two living larvae were randomly collected from each replicate at $6,12,24,48,72$ and $96 \mathrm{~h}$, and immediately frozen in liquid nitrogen before being stored at $-80{ }^{\circ} \mathrm{C}$ Twenty frozen midges were randomly selected from each treatment at each time interval for RNA preparations.

The dsRNAs were synthesized with cDNA of CYP6EV11 and GFP using MEGAscript T7 Kit (Ambion, Austin, TX, USA) following the manufacturer's instructions and were purified with ammonium acetate, water saturated phenol and chloroform. The $d s R N A$ was resuspended in RNase-free water, and quantitated at $260 \mathrm{~nm}$ using Nanodrop 2000 Spectrophotometer (Thermo Fisher Scientific Inc., Carlsbad, CA, USA). The quality and integrity of $d s R N A$ were verified by $1.0 \%$ agarose gel electrophoresis. The larvae were soaked in ${ } R R N A$ of CYP6EV11 $(2 \mu \mathrm{g} / \mu \mathrm{L})$, ten replicates containing thirty 4 th instar larvae in each replicate. The controls were soaked in $d s R N A$ of GFP $(2 \mu \mathrm{g} / \mu \mathrm{L})$ along with the $d s R N A$ of CYP6EV11 samples. Two living larvae were collected for each replicate at 3, 6, 24 and $72 \mathrm{~h}$, respectively, and then stored at $-80{ }^{\circ} \mathrm{C}$ for RNA extraction to measure the silence efficacy. To explore CYP6EV11 silencing in response to phenol stress, the survival larvae after soaking with the $1 \mu \mathrm{M}$ phenol for $1 \mathrm{~h}$ were soaked in the mixture of $2 \mu \mathrm{g} / \mu \mathrm{L} C Y P 6 E V 11 d s R N A$ and $1 \mu \mathrm{M}$ phenol. Twenty healthy larvae were collected at $3,6,24,48$, and $72 \mathrm{~h}$, respectively, and stored at $-80^{\circ} \mathrm{C}$ for RNA extraction to obtain CYP6EV11 gene expression profiles. The groups soaked in the mixture of $2 \mu \mathrm{g} / \mu \mathrm{L}$ GFP dsRNA and $1 \mu \mathrm{M}$ phenol were regarded as controls. All mortalities were recorded among treatments.

\subsection{Real-time RT-PCR Analysis}

Approximately $1 \mu \mathrm{g}$ of total RNA was reverse transcribed to cDNA using $1 \mu \mathrm{M}$ oligodeoxythymidine primer. Synthesized cDNAs were diluted to $100 \mu \mathrm{L}$ with sterile water and used as template for real-time PCR. The following primers were designed for amplification of the CYP6EV11 gene, F: $5^{\prime}$-GGCGGACAAGAATGGAAAGA- $3^{\prime}$ and R: $5^{\prime}$-GGCTGTCCAAGACACTTGAT- $3^{\prime}$. The Actin (F: 5'-AATGGGATCGCTTGGGTGCTTT-3' and R: $5^{\prime}$-TCAGCTTCACCCAATGTTGCCT-3') was selected as internal controls to calculate the relative expression level by the method of delta-delta CT method [40] and $2^{-\Delta \Delta \mathrm{Ct}}$ [41]. Amplifications were performed with the following parameters: $94{ }^{\circ} \mathrm{C}$ for $30 \mathrm{~s}$ followed by 45 cycles at $94{ }^{\circ} \mathrm{C}$ for $12 \mathrm{~s}, 60^{\circ} \mathrm{C}$ for $30 \mathrm{~s}, 72{ }^{\circ} \mathrm{C}$ for $40 \mathrm{~s}$, and $82{ }^{\circ} \mathrm{C}$ for $1 \mathrm{~s}$ for plate reading.

\section{Conclusions}

The CYP6EV11 in C. kiiensis was firstly identified and was found to be mostly upregulated under phenol stress. Compared with $d s G F P$, the CYPEV11 was effectively $92.7 \%$ silenced by RNAi in 4th instar C. kiiensis larvae soaked in dsCYP6EV11 for $6 \mathrm{~h}$. The CYP6EV11 transcript level and susceptibility of the $C$. kiiensis larvae were markedly decreased under phenol stress after CYP6EV11 
silencing. Therefore, the CYP6EV11 gene may be used as a sensitive molecular marker for phenol pollution monitoring.

Acknowledgments: This work was supported by Fundamental Research Funds for the Central Universities (grant no. 2572016DA1), the National Natural Science Foundation of China (31570642).

Author Contributions: Chuanwang Cao conceived and designed the experiments. Dong Chu and Qihui Zhang performed the experiments. Qihui Zhang, Lili Sun and Chuanwang Cao analyzed the data. Qihui Zhang and Chuanwang Cao wrote the paper.

Conflicts of Interest: The authors declare no conflict of interest.

\section{References}

1. Antonyraj, C.A.; Srinivasan, K. One-step hydroxylation of benzene to phenol over layered double hydroxides and their derived forms. Catal. Surv. Asia 2013, 17, 47-70. [CrossRef]

2. Michałowicz, J.; Duda, R.O.W. Analysis of chlorophenols, chlorocatechols, chlorinated methoxyphenols and monoterpenes in communal sewage of ŁÓDŹ and in the Ner River in 1999-2000. Water Air Soil Pollut. 2005, 164, 205-222. [CrossRef]

3. Dutta, N.N.; Brothakur, S.; Patil, G.S. Phase transfer catalyzed extraction of phenolic substances from aqueous alkaline stream. Sep. Sci. Technol. 1992, 27, 1435-1448. [CrossRef]

4. Huang, J.H.; Wang, X.G.; Jin, Q.Z.; Liu, Y.F.; Wang, Y. Removal of phenol from aqueous solution by adsorption onto OTMAC-modified attapulgite. J. Environ. Manag. 2007, 84, 229-236. [CrossRef] [PubMed]

5. Australian Water Research Council (AWRC). Australian Water Quality Criteria for Organic Compounds; Australian Water Research Council Technical Paper. No. 82; AWRC: Canberra, Australia, 1984; Volume 224.

6. DOE-MU. Water Quality Criteria and Standards for Malaysia. Vol. 4-Criteria and Standards for Organic Constituents; Prepared by Goh, S.H.; Yap, S.Y.; Lim, R.P.; DOE; Malaysia/IPT, University of Malaysia: Kuala Lumpur, Malaysia, 1986; Volume 224.

7. United States Environmental Protection Agency (USEPA). National Recommended Water Quality Criteria; Office of Water, Office of Science and Technology: Washington, DC, USA, 2009.

8. Cao, C.W.; Li, X.P.; Ge, S.L.; Sun, L.L.; Wang, Z.Y. Enzymatic activities as potential stress biomarkers of two substituted benzene compounds in Propsilocerus akamusi (Diptera: Chironomidae). Afr. J. Aquat. Sci. 2012, 37, 265-270. [CrossRef]

9. Nebert, D.W.; Russell, D.W. Clinical importance of the cytochromes P450. Lancet 2002, 360, 1155-1162. [CrossRef]

10. Liu, X.; Chen, J.; Yang, Z. Characterization and induction of two cytochrome P450 genes, CYP6AE28 and CYP6AE30, in Cnaphalocrocis medinalis: Possible involvement in metabolism of rice allelochemicals. Z. Naturforsch. C 2010, 65, 719-725. [CrossRef] [PubMed]

11. Poupardin, R.; Riaz, M.A.; Vontas, J.; David, J.P.; Reynaud, S. Transcription profiling of eleven cytochrome P450 s potentially involved in xenobiotic metabolism in the mosquito Aedes aegypti. Insect Mol. Biol. 2010, 19, 185-193. [CrossRef] [PubMed]

12. Cifuentes, D.; Chynoweth, R.; Guillén, J.; De la Rúa, P.; Bielza, P. Novel cytochrome P450 genes, CYP6EB1 and CYP6EC1, are over-expressed in acrinathrin-resistant Frankliniella occidentalis (Thysanoptera: Thripidae). J. Econ. Entomol. 2012, 105, 1006-1018. [CrossRef] [PubMed]

13. Musasia, F.K.; Isaac, A.O.; Masiga, D.K.; Omedo, I.A.; Mwakubambanya, R.; Ochieng, R.; Mireji, P.O. Sex-specific induction of CYP6 cytochrome P450 genes in cadmium and lead tolerant Anopheles gambiae. Malar. J. 2013, 12, 97. [CrossRef] [PubMed]

14. Edi, C.V.; Djogbénou, L.; Jenkins, A.M.; Regna, K.; Muskavitch, M.A.; Poupardin, R.; Jones, C.M.; Essandoh, J.; Kétoh, G.K.; Paine, M.J.; et al. CYP6 P450 enzymes and ACE-1 duplication produce extreme and multiple insecticide resistance in the malaria mosquito Anopheles gambiae. PLoS Genet. 2014, 10, e1004236. [CrossRef] [PubMed]

15. Sun, L.L.; Wang, Z.Y.; Zou, C.S.; Cao, C.W. Transcription profiling of 12 Asian gypsy moth (Lymantria dispar) cytochrome P450 genes in response to insecticides. Arch. Insect Biochem. Physiol. 2014, 85, 181-194. [CrossRef] [PubMed] 
16. Zimmer, C.T.; Bass, C.; Williamson, M.S.; Kaussmann, M.; Wlfel, K.; Gutbrod, O.; Nauen, R. Molecular and functional characterization of CYP6BQ23, a cytochrome P450 conferring resistance to pyrethroidsin European populations of pollen beetle, Meligethes aeneus. Insect Biochem. Mol. Biol. 2014, 45, 18-29. [CrossRef] [PubMed]

17. Martínez-Guitarte, J.L. Transcriptional activity of detoxification genes is altered by ultraviolet filters in Chironomus riparius. Ecotoxicol. Environ. Saf. 2018, 149, 64-71. [CrossRef] [PubMed]

18. Martínez-Paz, P. Response of detoxification system genes on Chironomus riparius aquatic larvae after antibacterial agent triclosan exposures. Sci. Total Environ. 2018, 624, 1-8. [CrossRef] [PubMed]

19. Cao, C.W.; Sun, L.L.; Niu, F.; Liu, P.; Chu, D.; Wang, Z.Y. Effects of phenol on metabolic activities and transcription profiles of cytochrome P450 enzymes in Chironomus kiinensis larvae. Bull. Entomol. Res. 2016, 106, 73-80. [CrossRef] [PubMed]

20. Martínez-Paz, P.; Morales, M.; Martínez-Guitarte, J.L.; Morcillo, G. Characterization of a cytochrome P450 gene (CYP4G) and modulation under different exposures to xenobiotics (tributyltin, nonylphenol, bisphenol A) in Chironomus riparius aquatic larvae. Comp. Biochem. Physiol. C Toxicol. Pharmacol. 2012, 155, 333-343. [CrossRef] [PubMed]

21. Nair, P.M.; Park, S.Y.; Choi, J. Characterization and expression of cytochrome p450 cDNA (CYP9AT2) in Chironomus riparius fourth instar larvae exposed to multiple xenobiotics. Environ. Toxicol. Pharmacol. 2013, 36, 1133-1140. [CrossRef] [PubMed]

22. Tang, G.; Yao, J.; Zhang, X.; Liu, N.; Zhu, K.Y. Comparison of gene expression profiles in the aquatic midge (Chironomus tentans) larvae exposed to two major agricultural pesticides. Chemosphere 2018, 194, 745-754. [CrossRef] [PubMed]

23. Tang, G.; Yao, J.; Li, D.; He, Y.; Zhu, Y.C.; Zhang, X.; Zhu, K.Y. Cytochrome P450 genes from the aquatic midge Chironomus tentans: Atrazine-induced up-regulation of CtCYP6EX3 enhanced the toxicity of chlorpyrifos. Chemosphere 2017, 186, 68-77. [CrossRef] [PubMed]

24. Broza, M.; Halpern, M.; Gahanma, L.; Inbar, M. Nuisance chironomids in waste water stabilization ponds: Monitoring and action threshold assessment based on public complaints. J. Vector Ecol. 2003, 28, 31-36. [PubMed]

25. Cao, C.W.; Sun, L.L.; Wen, R.R.; Li, X.P.; Wu, H.Q.; Wang, Z.Y. Toxicity and affecting factors of Bacillus thuringiensis var. israelensis on Chironomus kiiensis larvae. J. Insect Sci. 2012, 12, 1-8. [CrossRef] [PubMed]

26. Cao, C.W.; Wang, Z.Y.; Niu, C.Y.; Desneux, N.; Gao, X.W. Transcriptome profiling of Chironomus kiinensis under phenol stress using solexa sequencing technology. PLoS ONE 2013, 8, e58914. [CrossRef] [PubMed]

27. Hasemann, C.A.; Kurumbail, R.G.; Boddupalli, S.S.; Peterson, J.A.; Deisenhofer, J. Structure and function of cytochrome P450: A comparative analysis of three crystal structures. Structure 1995, 3, 41-62. [CrossRef]

28. Feyereisen, R. Insect cytochrome P450. In Comprehensive Molecular Insect Science; Gilbert, L.I., Iatrou, K., Gill, S., Eds.; Elsevier: Oxford, UK, 2005; Volume 4, pp. 1-77.

29. Rewitz, K.F.; Rybczynski, R.; Warren, J.T.; Gilbert, L.I. Identification, characterization and developmental expression of Halloween genes encoding P450 enzymes mediating ecdysone biosynthesis in the tobacco hornworm, Manduca sexta. Insect Biochem. Mol. Biol. 2006, 36, 188-199. [CrossRef] [PubMed]

30. Schuler, M.A. The role of cytochrome P450 monooxygenases in plant-insect interactions. Plant Physiol. 1996, 112, 1411-1419. [CrossRef] [PubMed]

31. Li, X.C.; Schuler, M.A.; Berenbaum, M.R. Molecular mechanisms of metabolic resistance to synthetic and natural xenobiotics. Annu. Rev. Entomol. 2007, 52, 231-253. [CrossRef] [PubMed]

32. Bass, C.; Carvalho, R.A.; Oliphant, L.; Puinean, A.M.; Field, L.M.; Nauen, R.; Williamson, M.S.; Moores, G.; Gorman, K. Overexpression of a cytochrome P450 monooxygenase, CYP6ER1, is associated with resistance to imidacloprid in the brown planthopper, Nilaparvata lugens. Insect Mol. Biol. 2011, 20, 763-773. [CrossRef] [PubMed]

33. David, J.P.; Ismail, H.M.; Chandor-Proust, A.; Paine, M.J. Role of cytochrome P450s in insecticide resistance: impact on the control of mosquito-borne diseases and use of insecticides on Earth. Philos. Trans. R. Soc. Lond. B Biol. Sci. 2013, 368, 20120429. [CrossRef] [PubMed]

34. Yang, Y.X.; Zhang, Y.X.; Yang, B.J.; Fang, J.C.; Liu, Z.W. Transcriptomic responses to different doses of cycloxaprid involved in detoxification and stress response in the whitebacked planthopper, Sogatella furcifera. Entomol. Exp. Appl. 2016, 158, 248-257. [CrossRef] 
35. Sun, L.L.; Wang, Z.Y.; Wu, H.Q.; Liu, P.; Zou, C.S.; Xue, X.T.; Cao, C.W. Role of ocular albinism type 1 (OA1) GPCR in Asian gypsy moth development and transcriptional expression of heat-shock protein genes. Pestic. Biochem. Physiol. 2016, 126, 35-41. [CrossRef] [PubMed]

36. Lin, W.; Yu, Y.X.; Zhou, P.; Zhang, J.H.; Dou, L.D.; Hao, Q.; Chen, H.J.; Zhu, S.F. Identification and Knockdown of the Olfactory Receptor (OrCo) in Gypsy Moth, Lymantria dispar. Int. J. Biol. Sci. 2015, 11, 772-780. [CrossRef] [PubMed]

37. Niu, X.P.; Kassa, A.; Hu, X.; Robeson, J.; McMahon, M.; Richtman, N.M.; Steimel, J.P.; Kernodle, B.M.; Crane, V.C.; Sandahl, G.; et al. Control of Western Corn Rootworm (Diabrotica virgifera virgifera) Reproduction through Plant-Mediated RNA Interference. Sci Rep. 2017, 7, 12591. [CrossRef] [PubMed]

38. Lu, Y.; Park, Y.; Gao, X.; Zhang, X.; Yao, J.; Pang, Y.P.; Jiang, H.; Zhu, K.Y. Cholinergic and non-cholinergic functions of two acetylcholinesterase genes revealed by gene-silencing in Tribolium castaneum. Sci. Rep. 2012, 2, 288. [CrossRef] [PubMed]

39. Tamura, K.; Peterson, D.; Peterson, N.; Steche, G.; Nei, M.; Kumar, S. MEGA5: Molecular evolutionary genetics analysis using maximum likelihood, evolutionary distance, and maximum parsimony methods. Mol. Biol. Evol. 2011, 28, 2731-2739. [CrossRef] [PubMed]

40. Pfaffl, M.W.; Horgan, G.W.; Dempfle, L. Relative expression software tool (REST) for group-wise comparison and statistical analysis of relative expression results in real-time PCR. Nucleic Acids Res. 2002, 30, e36. [CrossRef] [PubMed]

41. Livak, K.J.; Schmittgen, T.D. Analysis of relative gene expression data using real-time quantitative PCR and the 2(-Delta Delta C(T)) Method. Methods 2001, 25, 402-408. [CrossRef] [PubMed]

(C) 2018 by the authors. Licensee MDPI, Basel, Switzerland. This article is an open access article distributed under the terms and conditions of the Creative Commons Attribution (CC BY) license (http:/ / creativecommons.org/licenses/by/4.0/). 